\title{
Phytochemical Composition of Aqueous Crude Extracts of Selected Pesticidal Plants used against Brassica Vegetable Pests
}

\author{
Racheal Lamara ${ }^{1}$, Morgan Andama ${ }^{2}$ and Eunice A. Olet $^{1}$ \\ ${ }^{1}$ Department of Biology, Mbarara University of Science and Technology, P.O Box 1410, \\ Mbarara, Western Region, Uganda \\ ${ }^{2}$ Department of Biology, Muni University, P.O. Box725, Arua, North West Region, Uganda \\ *Corresponding author
}

\section{A B S T R A C T}

\section{Keywords}

Aqueous Extracts, Pesticidal Plants,

Phytochemicals,

Quantitative

Analysis

\section{Article Info}

Accepted:

15 December 2019

Available Online:

20 January 2020
The phytochemistry of five plants (Phytolacca dodecandra, Azadirachta indica, Capsicum frutescens, Allium cepa and Tagetes minuta) was determined to evaluate their potential as sources of alternative pesticides against Brassica vegetable pests. Crude aqueous plant extracts were prepared, on which quantitative and qualitative analysis were performed using standard methods. Tannins and alkaloids were found in all plants examined with their highest quantities obtained in T. minuta at 0.4494 $\mathrm{mgml}^{-1}$ and $0.1560 \mathrm{mgml}^{-1}$ respectively. Steroids were highest in $C$. frutescens and $A$. indica at $2.2791 \mathrm{mgml}^{-1}$ each. Saponins were more in $P$. dodecandra $(31.06 \%)$ and flavonoids were highest in $C$. frutescens $(26.13 \%)$. It was evident that $C$. frutescens, $A$. indica and $T$. minuta had higher quantities of phytochemicals. This may be responsible for them being more effective pesticides against Brassica vegetable pests than Allium cepa and $P$. dodecandra which had lower quantities or absence of some phytochemicals.

\section{Introduction}

Agriculture has from time immemorial been faced with the destructive activities of numerous pests like insects, fungi and weeds leading to a radical decrease in yields. Owing to this, control measures to minimize their effects on crops are vital. For many years, chemical pesticides have proved to be effective in controlling pests and hence boosting crop production so much that many farmers have abandoned cultural pest control methods and turned all their attention to chemical pesticides(Baidoo and Mochiah, 2016). However, these pesticides have been criticized for the negative impacts associated 
with their use such as environmental contamination that transfers chemical residues along the food chain, development of pesticide resistance in some pests, increased health hazards to people, threats to biodiversity and/or contributing to genetic defects in subsequent generations, and increased unproductiveness of arable land(Baidoo et al., 2012; Naqqash et al., 2016.

In light of these developments, there has been a renewed interest in the use of botanicals, plant derived products, for crop protection over the last few decades(Devi and Gupta, 2000; Facknath, 2006; Ssekyewa et al., 2008; Tewary et al., 2005; Miresmailli and Isman, 2014). Generally, the use of botanical pesticides is more sustainable and has a lower environmental impact than synthetic pesticides (Devanand and Rani, 2008).

The phytochemicals from these plants are responsible for their pesticidal potentials. Phytochemicals are secondary metabolites, biosynthesized from primary metabolites, eliciting pharmacological or toxicological effects in man and animals(Bernhoft, 2010).

Complex mixtures of secondary compounds in plant extracts were reported to contribute to a great deal to synergism, which enhances the joint action of active compounds against pests and reduces the rate of resistance development(Jacobs et al., 2015). Studies by several researchers such as De Geyter et al., (2007) and Adeniyi et al., (2010)have shown that the most important phytochemicals well known to confer pesticidal properties are alkaloids, terpenoids, steroids, phenolic compounds, saponins and tannins. This study was therefore, designed to determine and compare the phytochemical components of crude aqueous extracts of five selected plant species (A. indica, $C$. frutescens, $P$. dodecandra, Allium cepa and T. minuta) used against pests of Brassica vegetables. The results obtained are key in making recommendations concerning the cultivation and domestication of certain species whose bioactive substances can be valued as pesticides.

\section{Materials and Methods}

\section{Plant Collection}

Plant leaves of $A$. indica, T. minuta and $P$. dodecandra and $C$. frutescens fruits were harvested from Katanda Sub-County, Rubirizi District in Western Uganda in January, 2019.

Allium cepa bulbs were purchased from the trading centers in the same sub-county. The plant samples were identified at the Department of Biology, Mbarara University of Science and Technology, Uganda.

\section{Plant Aqueous Extract Preparation}

The fresh plant samples were washed thoroughly with running tap water to remove dust, pollen and other particles. They were then ground using a mechanical grinder and the ground samples extracted with 1 liter of distilled water for 24 hours at ambient temperature. The aqueous extract was filtered, the residue discarded and the solvent evaporated in an oven for 5 days at $65^{\circ} \mathrm{C}$ to yield crude extracts. These were packed into small labeled bottles, well covered and kept in a pharmaceutical refrigerator. An amount of $2.0 \mathrm{~g}$ of each crude extract was weighed and dissolved in $20 \mathrm{~mL}$ of distilled water in separate labeled beakers to obtain the aqueous plant extracts used for phytochemical screening.

\section{Phytochemical screening}

This was done using chemicals of analytical grade following methods described by Trease and Evans (2009) and Kokate et al., (2010). 


\section{Alkaloids}

An amount of $2 \mathrm{~mL}$ of the plant extract was boiled with $2 \mathrm{~mL}$ of $2 \%$ sulphuric acid for two minutes, cooled then a few drops of Dragendorff's reagent (DR) added. A reddish brown precipitate was formed indicating the presence of alkaloids.

\section{Saponins}

A $2 \mathrm{~mL}$ amount of the extract was shaken with $5 \mathrm{ml}$ of distilled water and then heated to boil. Frothing indicated the presence of saponins.

\section{Flavonoids}

The extract $(2 \mathrm{~mL})$ was mixed with $3 \mathrm{~mL}$ of $1 \%$ sodium hydroxide and dilute hydrochloric acid was added. The appearance of a yellow colouration indicated the presence of flavonoids.

\section{Tannins}

Exactly $2 \mathrm{~mL}$ of the extract was mixed with 4 drops of ferric chloride solution. Formation of a blue colour indicated the presence of hydrolysable tannins while the formation of a green colour indicated the presence of condensed tannins.

\section{Steroids}

To $2 \mathrm{ml}$ of the extract was added 4 drops of acetic anhydride and the mixture boiled and cooled. $2 \mathrm{~mL}$ of concentrated sulphuric acid was added down the side of the tube. Formation of a brown ring at the junction of the two layers and the upper layer turning green indicated the presence of steroids.

\section{Quantification of Phytochemicals}

Analytical method for quantitative determination of the phytochemicals were carried out according to Amadi, et al.,(2004); Ejikeme, et al.,(2014) and Obadoni and Ochuko (2001).

\section{Alkaloids}

The quantification of alkaloids was done using quinine sulphate stock solution (prepared by dissolving $0.1 \mathrm{~g}$ in $100 \mathrm{~mL}$ distilled water) as the standard solution. Several dilutions of the stock solution were made by pipetting out 0.2 , $0.4,0.6,0.8,1.0 \mathrm{~mL}$ of the stock solution into separate test tubes and diluting to $10 \mathrm{~mL}$ volume with distilled water. To each test solution, $3 \mathrm{~mL}$ of DR (prepared by mixing 0.8 $\mathrm{g}$ bismuth nitrate pentahydrate in $40 \mathrm{~mL}$ distilled water and $10 \mathrm{~mL}$ glacial acetic acid, and a solution of $8.0 \mathrm{~g}$ of potassium iodide in $20 \mathrm{~mL}$ distilled water) were added followed by $3 \mathrm{~mL}$ of thiourea solution (prepared by dissolving $3.0 \mathrm{~g}$ in $100 \mathrm{~mL}$ distilled water). Using a spectrophotometer (UV 6705/Vis. with $1 \mathrm{~cm}$ UV quartz cell), the absorbance values of the test solutions formed were measured at a wave length of $435 \mathrm{~nm}$ against colorless reagent (distilled water) blanks. A calibration curve of absorbance versus concentration stock solution was plotted and found to be linear(Figure 1).

Exactly $10 \mathrm{~mL}$ of each plant extract (prepared by dissolving $0.1 \mathrm{~g}$ of crude sample in $100 \mathrm{~mL}$ of distilled water in a beaker) was pipetted into five separate labeled test tubes. To each, 3 $\mathrm{mL}$ of DR were added followed by $3 \mathrm{~mL}$ of thiourea solution. The absorbance was measured at $435 \mathrm{~nm}$ against the blank of distilled water. The obtained value of the absorbance was substituted in the linear equation of the calibration curve to get the concentration of the alkaloids in $\mathrm{mgml}^{-1}$.

\section{Tannins}

Tannins were quantified using tannic acid stock solution (prepared by dissolving $0.1 \mathrm{~g}$ in 
$100 \mathrm{~mL}$ of distilled water) as the standard solution. Several dilutions of the stock solution were made by pipetting out $0.2,0.4$, $0.6,0.8$, and $1.0 \mathrm{~mL}$ stock solution into separate test tubes and diluting to $10 \mathrm{~mL}$ volume with distilled water. To each test solution, $3 \mathrm{~mL}$ of iron III chloride (prepared by dissolving 5.0 gin $100 \mathrm{~mL}$ of distilled water) was added. Using a spectrophotometer, the absorbance values of the test solutions formed were measured at a wave length of 550 $\mathrm{nm}$ against colorless reagent (distilled water) blanks. A calibration curve of absorbance versus concentration was also plotted (Figure 2).

A $10 \mathrm{~mL}$ amount of each plant extract (prepared by dissolving $0.1 \mathrm{~g}$ of crude sample in $100 \mathrm{~mL}$ of distilled water) was pipetted out into five separate labeled test tubes. To each, 3 $\mathrm{mL}$ of iron III chloride were added. The absorbance was measured at $550 \mathrm{~nm}$ against the blank of distilled water. The obtained value of the absorbance was substituted in the linear equation of the calibration curve to get the concentration of the tannins in $\mathrm{mgml}^{-1}$.

\section{Steroids}

Steroids were quantified using steroid stock solution (prepared by dissolving $1.0 \mathrm{~g}$ in 100 $\mathrm{mL}$ of distilled water) as the standard. Several dilutions were made by pipetting out $0.6,0.8$, 1.0 and $1.2 \mathrm{~mL}$ of stock solution into separate test tubes and diluting to $10 \mathrm{~mL}$ volume with distilled water. To each test solution, $3 \mathrm{~mL}$ of acetic anhydride, $3.30 \%$, was added followed by $3 \mathrm{~mL}$ of concentrated sulphuric acid, $98 \%$. Using a spectrophotometer, the absorbance values of the test solutions formed were measured at a wave length of $513 \mathrm{~nm}$ against colorless reagent (distilled water) blanks. A calibration curve of absorbance versus concentration was plotted (Figure 3). Exactly $10 \mathrm{~mL}$ of each plant extract (prepared by dissolving $1.0 \mathrm{~g}$ of crude sample in $10 \mathrm{~mL}$ of distilled water) was pipetted out into five separate labeled test tubes. To each, $3 \mathrm{~mL}$ of acetic anhydride was added followed by $3 \mathrm{~mL}$ of concentrated sulphuric acid. The absorbance was measured at $513 \mathrm{~nm}$ against the blank of distilled water. The obtained value of the absorbance was substituted in the linear equation of the calibration curve to get the concentration of the steroids in $\mathrm{mgml}^{-1}$.

\section{Flavonoids}

Crude extracts $(5.0$ g) were weighed and dissolved in $20 \mathrm{~mL}$ of distilled water in a beaker. The mixture was filtered, forming the aqueous phase that was transferred into a 250 $\mathrm{mL}$ separating funnel to which $40 \mathrm{~mL}$ ethyl acetate (organic phase) was added. The two were vigorously shaken and partitioned successfully after which the organic phase was collected into a clean pre-weighed beaker whereas the aqueous phase was retained in the funnel. To the aqueous phase was added 40 $\mathrm{mL}$ of $\mathrm{n}$-butanol, the layers were vigorously shaken and partitioned. The aqueous phase was discarded while the organic phase was recovered and combined with the ethyl acetate extract. The samples were dried in the oven for 7 days at $65^{\circ} \mathrm{C}$ and thereafter weighed and flavonoid yield was calculated as a percentage using the equation below.

\section{Flavonoid yield \\ $=\frac{\text { mass of crude flavonoids }}{\text { mass of dry aqueous extracts }} \times 100 \%$}

\section{Saponins}

Crude extract $(12.5 \mathrm{~g})$ were weighed and dissolved in $30 \mathrm{~mL}$ of distilled water in a beaker forming a uniform mixture that was the aqueous phase. This was transferred into a 250 $\mathrm{mL}$ separating funnel to which $20 \mathrm{~mL}$ diethyl ether (organic phase) was added to de-fat the extract. The two were vigorously shaken and partitioned successfully, the aqueous phase 
was retained in the funnel whereas the organic phase was discarded. To the aqueous phase was then added $30 \mathrm{~mL}$ of n-butanol to extract the saponins, the layers were vigorously shaken and partitioned. Thereafter the aqueous phase was discarded while the organic phase was retained in the funnel. To the organic phase, $100 \mathrm{~mL}$ of $5 \%$ sodium chloride was added to wash out impurities in the n-butanol. The liquids were shaken vigorously and partitioned and then the n-butanol phase was collected in a clean dry pre-weighed beaker. The beaker was labeled and dried in the oven at $65^{\circ} \mathrm{C}$ to a constant weight. The saponin yield was calculated as a percentage using the equation below:

\section{Saponin yield $=$ $\frac{\text { mass of crude saponin }}{\text { mass of dry aqueos extracts }} \times 100 \%$}

\section{Data Analysis}

Means of triplicate analyses were calculated and data was expressed as mean \pm standard deviation. One-way analysis of variance (ANOVA) with Post hoc (Tukey HSD) statistical analysis was performed using SPSS Version 22 software for comparison between two or more treatments. A difference in ANOVA was considered to be statistically significant when $\mathrm{p} \leq 0.05$.

\section{Results and Discussion}

\section{Percentage yield of aqueous extracts of the pesticidal plants}

Table 1 shows the percentage yield of aqueous extract of the plants. The crude extract of the C. frutescens fruitcontains a greater proportion by mass of the component compounds followed by that of the Allium cepa bulbs. The leaf extracts of $T$. minuta, A. indica and $P$. dodecandra contains the least proportion of the component compounds respectively.

\section{Phytochemical components of the pesticidal plants}

The phytochemicals detected were alkaloids, saponins, flavonoids, tannins, and steroidsas shown in Table 2. The results showed that all plants contained alkaloids and tannins. Steroids were absent in only $P$. dodecandra and flavonoids absent in T. minuta. Saponins were present only in $P$. dodecandraand $C$. frutescens.

\section{Phytochemical Quantification}

Table 3 shows the quantitative estimates of the phytochemicals in the plant extracts and their comparison using ANOVA, F test. There were highly significant differences in the mean concentrations of the phytochemicals across the five plant extracts $(\mathrm{p}=0.000)$. Alkaloids and tannins were highest in T. minuta extract at $0.1556 \pm 0.000 \mathrm{mgml}^{-1}$ and $0.4494 \pm 0.027$ $\mathrm{mgml}^{-1}$ respectively. The same phytochemicals were lowest in Allium cepa extracts at $0.0871 \pm 0.001 \mathrm{mgml}^{-1}$ and 0.0407 $\pm 0.002 \mathrm{mgml}^{-1}$ respectively. $C$. frutescens and $A$. indica extracts gave the highest concentrations of steroids each at 2.2791 $\mathrm{mgml}^{-1}$ and the least in Allium cepa at 0.5248 $\pm 0.017 \mathrm{mgml}^{-1}$. Flavonoids were most in $C$. frutescens at $26.134 \pm 0.058 \%$ and least in $P$. dodecandra at $12.134 \pm 0.006 \%$. Saponins were found in $P$. dodecandra and $C$. frutescens and were estimated at $31.059 \pm$ $0.062 \%$ and $7.786 \pm 0.058 \%$ respectively. In a few cases, concentrations of some phytochemicals between plant extracts were statistically equal namely: alkaloid and flavonoid concentrations in $A$. indica and Allium cepa extracts with p-values of 0.1 and 0.759 respectively; also, tannin and steroid concentrations of $A$. indica and $C$. frutescens extracts with p-values of 0.995 and 1.0 respectively. Phytochemicals are the major source of pharmaceuticals, food additives, fragrances, pesticides, and herbicides (Okwu, 2005; Ramawat and Dass, 2009). However, 
isolation of the pure, active constituents from plants for these purposes is a long and tedious process. Therefore, it is necessary to have methods available which eliminate unnecessary separation procedures such as chemical screening. Ndam et al.,(2014)states that this method is performed to allow localization and targeted isolation of new or useful constituents with potential activities. The authors continue to state that this procedure enables recognition of known metabolites in extracts or at the earliest stages of separation and is thus economically very important.

In the present study, phytochemical analysis was performed on aqueous plant extracts of $A$. indica, T. minuta, Allium cepa, C. frutescens and $P$. dodecandra.The phytochemicals, alkaloids, saponins, flavonoids, tannins, and steroids, were found to be present in the pesticidal plants in different proportions. The phytochemicals, when ingested by animals, exhibit various pharmacological and biochemical actions and hence may be responsible for their pesticidal properties. This concurs with related studies done by De Geyter et al.,(2007)in which it was highlighed that secondary metabolites such as phenolic compounds, saponins, alkaloids, flavonoids and terpenoids have been identified to exhibit strong activities against several pathogens and insect pests.

Phenolic compounds are one of the largest groups of plant metabolites (Singh, et al., 2007) and owing to this, intensive studies have been undertaken with regard to their toxicity (Goławska, 2006). Halkier(1999) reports that phenols play important roles in plant herbivore and pathogen interactions. The antioxidant properties of pesticidal plants have been described by various studies to be linked to presence of phenolic compounds(Krings \&
Berger, 2001). They usually produce natural oxidants such as flavonoids, phenolic acids, to copherols inter alia(Ali et al., 2010). Dixon (1999) while studying the biochemistry of flavonoids stated that they play a vital role of resistance in legumes. This, they achieve via their capacity to modulate the feeding behavior of insects(Hedin and Waage, 1986). Tannins have been reported to exert their action on plant pests by a combination of mechanisms that includes iron chelation and enzyme inhibition (Karamanoli et al., 2011).

Further still, Doluietal.(2010)reported that tannins combined with protein to inhibit enzyme activity and reduce the availability of protein in haemolymph in insects.Chaieb (2010)extensively reviewed insecticidal effects of saponins, linking their insecticidal activity with cholesterol which results in impaired ecdysteroid synthesis. Some of the reported observed effects of saponins are increased mortality, lowered food intake, weight reduction, retardation in development and decreased reproduction (ibid.). Plant alkaloid toxicity can be quite diversified, but often involves neurotoxicity or cell signaling disruption according to Mithöfer and Boland (2012). The authors noted further that toxicity also arose by enzymatic alterations that affect physiological processes, inhibits synthesis of DNA and repair mechanisms by intercalating with nucleic acids. The negative effects of their contact with pests include reduced ovary development, mobility, and survivorship (ibid.).

In fact, complex mixtures of secondary compounds in plant extracts were reported to contribute to a great deal for synergism, which enhances the joint action of active compounds against insect and reduces the rate of resistance development(Feng and Isman, 1995). 
Table.1 Percentage yield of aqueous extract of the pesticidal pests

\begin{tabular}{|c|c|}
\hline Crude extract & \% Yield \\
\hline A. indica & 4.78 \\
\hline C. frutescens & 11.69 \\
\hline T. minuta & 4.96 \\
\hline Allium cepa & 9.84 \\
\hline P. dodecandra & 4.75 \\
\hline
\end{tabular}

Table.2 Phytochemical components of the pesticidal plants extracts

\begin{tabular}{|c|c|c|c|c|c|}
\hline Plant sample & Alkaloids & Tannins & Steroids & Flavonoids & Saponins \\
\hline P. dodecandra & + & +++ & - & +++ & ++ \\
\hline Allium cepa & + & + & + & +++ & - \\
\hline C. frutescens & + & + & + & +++ & + \\
\hline A. indica & + & ++ & + & +++ & - \\
\hline T. minuta & + & ++ & + & - & - \\
\hline
\end{tabular}

KEY-Heavily present:+++ Slightly present:++ Present: + Absent:-

Table.3 Quantitative estimates of phytochemicals of extracts from sample plants

\begin{tabular}{|c|c|c|c|c|c|}
\hline Sample & $\begin{array}{c}\text { Alkaloids } \\
\left(\mathrm{mgml}^{-1}\right)\end{array}$ & $\begin{array}{l}\text { Tannins } \\
\left(\mathrm{mgml}^{-1}\right)\end{array}$ & $\begin{array}{l}\text { Steroids } \\
\left(\mathrm{mgml}^{-1}\right)\end{array}$ & $\begin{array}{c}\text { Flavonoids } \\
(\%)\end{array}$ & $\begin{array}{c}\text { Saponins } \\
(\%)\end{array}$ \\
\hline P. dodecandra & $0.1312 \pm 0.000^{\mathrm{a}}$ & $0.1537 \pm 0.008^{a}$ & (1) & $12.134 \pm 0.006^{\mathrm{a}}$ & $31.059 \pm 0.062^{a}$ \\
\hline Allium сера & $0.0871 \pm 0.001^{b}$ & $0.0407 \pm 0.002^{b}$ & $0.5248 \pm 0.017^{\mathrm{a}}$ & $20.534 \pm 0.064^{b}$ & \\
\hline C. frutescens & $0.1045 \pm 0.000^{c}$ & $0.34 \pm 0.014^{\mathrm{c}}$ & $2.2791^{\mathrm{b}}$ & $26.134 \pm 0.058^{c}$ & $7.786 \pm 0.058^{b}$ \\
\hline A. indica & $0.0889 \pm 0.001^{\mathrm{b}}$ & $0.3346 \pm 0.020^{b}$ & $2.2791^{\mathrm{b}}$ & $21.266 \pm 0.064^{\mathrm{c}}$ & 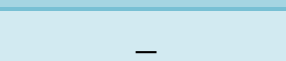 \\
\hline T. minuta & $0.1560 \pm 0.000^{d}$ & $0.4494 \pm 0.027^{d}$ & $0.9387 \pm 0.013^{c}$ & - & - \\
\hline p-value & 0.000 & 0.000 & 0.000 & 0.000 & 0.000 \\
\hline
\end{tabular}

Values are means \pm standard deviation of three replicates $(N=3)$, means in a column with the same letter are not significantly different $(p>0.05)$.

Fig.1 Standard calibration curve of quinine sulphate stock solution

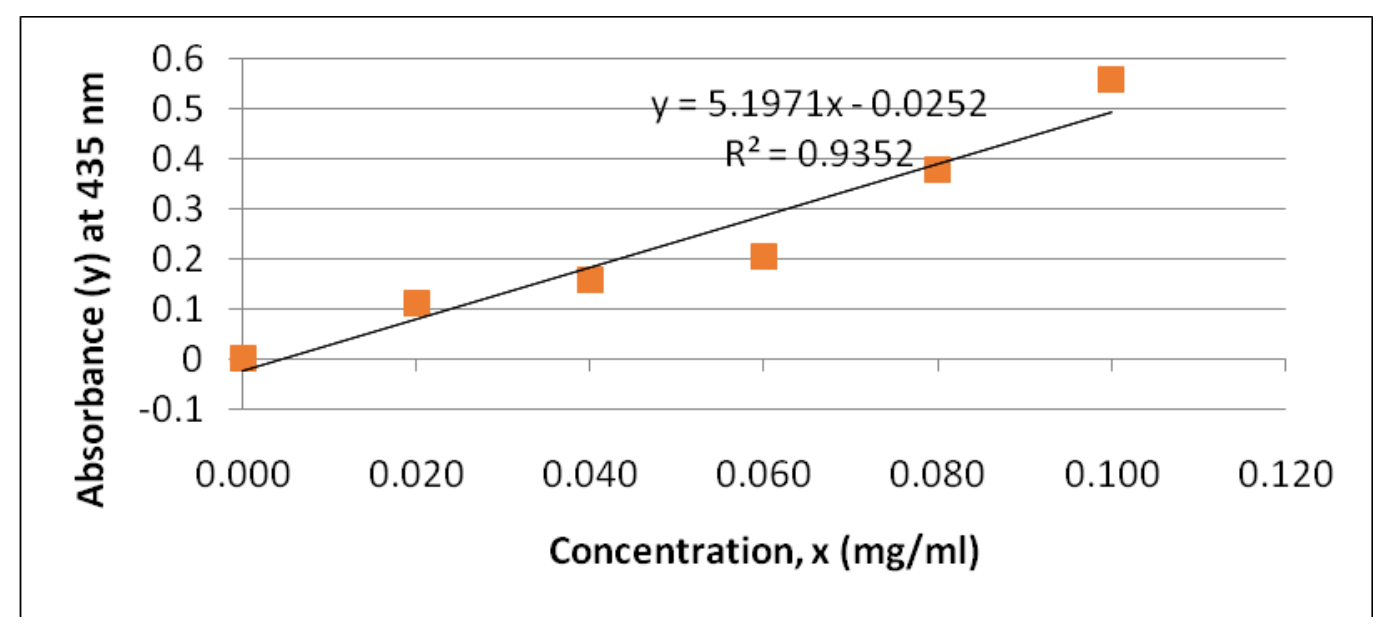


Fig.2 Standard calibration curve of tannic acid stock solution

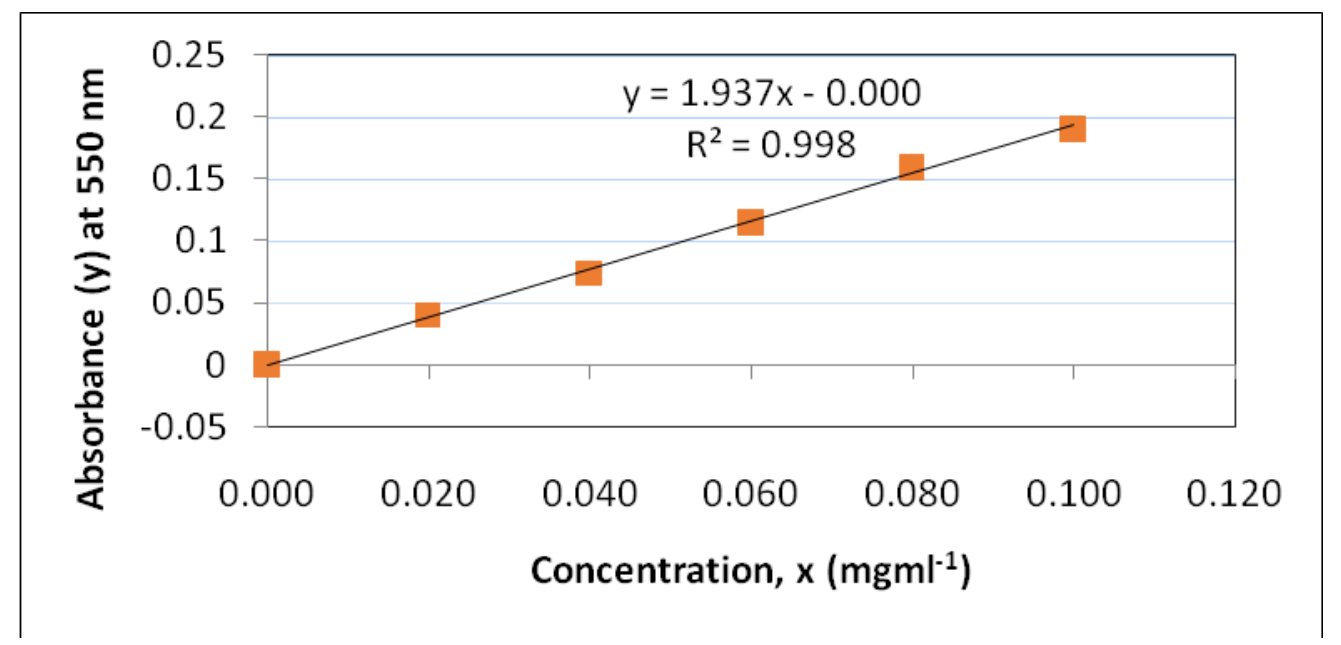

Fig.3 Standard calibration curve of steroid standardstock solution

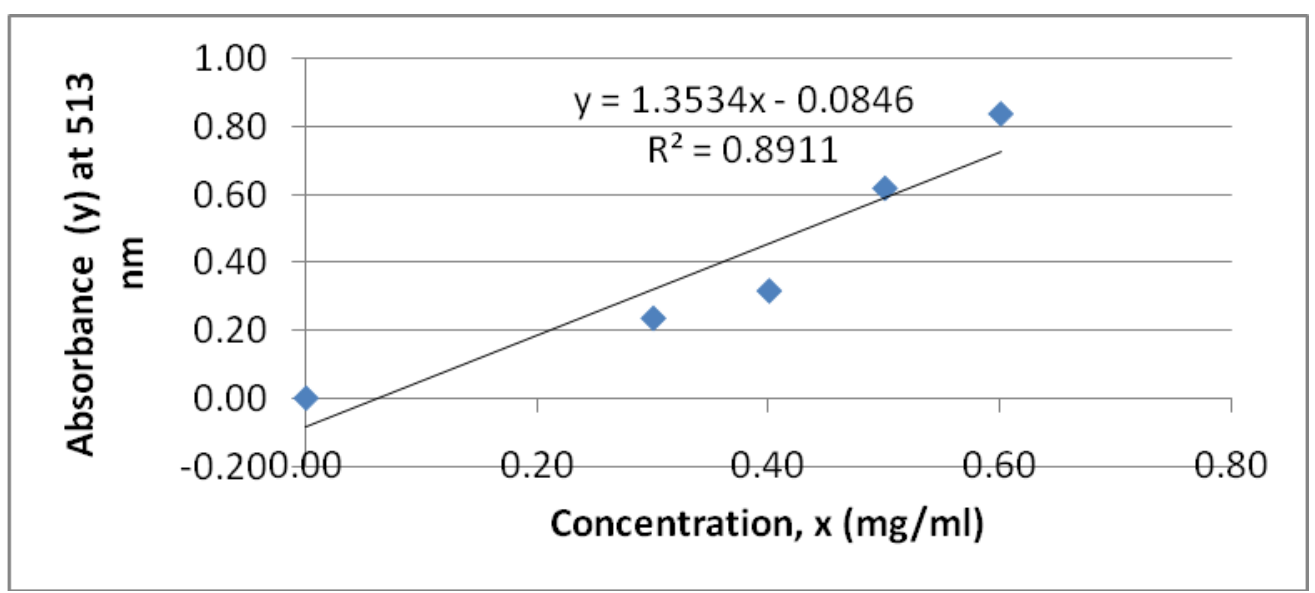

Notwithstanding, Anupam et al.,(2012)noted that the effectiveness of phytochemicals against crop pests can vary significantly depending on plant species, plant parts used, age of plant parts (young, mature or senescent), as well as the solvent used during extraction. Trease and Evans (2009)go ahead to state that the quantity and the composition of bioactive compounds present in plants are influenced by the genotype, extraction procedure, geographic and climatic conditions, and the growth phase of the plants. They continue to say that this makes it difficult to compare data with the literature because several variables influence the results.
Results from the present investigation showed that A. indica, T. minuta, P. dodecandra, Allium cepa and $C$. frutescens are very rich in phytochemicals, even though the phytochemical analysis of the plants revealed some differences in their constituents. However, aqueous extracts of $C$. frutescents, $A$. indica and T.minuta had higher quantities of bioactive compounds than Allium cepa, and $P$. dodecandra extracts contributing to their increased effectiveness for pest control.

These results suggest that these plants are a valuable reservoir of bioactive compounds of substantial pesticidal merit. Aqueous extracts 
of $C$. frutescents, A. indica and T.minuta are especially beneficial for managing Brassica vegetable pests as they contained the highest quantities of the bioactive components. This study may be useful in exploring the pharmacological and biosynthetic activity of these plants further.

\section{Acknowledgement}

We are grateful to the Departments of Biology and Pharmacy of Mbarara University of Science and Technology, for provision of space and facilities at the Laboratory for this study. Financial support to carry out this work was provided by Makerere-SIDA Research Programme Scholarship.

\section{References}

Adeniyi, S. A., Orjiekwe, C. L., Ehiagbonare, J. E., and Arimah, B. D. 2010. Preliminary phytochemical analysis and insecticidal activity of ethanolic extracts of four tropical plants (Vernonia amygdalina, Sida acuta, Ocimum gratissimum and Telfaria occidentalis) against bean weevils (Acanthscelides obtectus). International Journal of Physical Sciences. 8(4): 753-762.

Ali, A., Rizvi, P. Q., and Khan, F. R. 2010. Bio-efficacy of some plant leaf extracts against mustard aphid, Lipaphis erysimi Kalt. on Indian mustard, Brassica juncea. Journal of Plant Protection.50(2): 130-132.

Amadi, B. A., Agomuo, E. N., and Ibegbulem, C. O. 2004. Research Methods in Biochemistry. Owerri, Nigeria: Supreme Publishers.

Anupam, G., Nandita, C., and Goutam, C. 2012. Plant extracts as potential mosquito larvicides. Indian J. Med. Res.135(5): 581-598.

Baidoo, P. K., and Mochiah, M. B. 2016. Comparing the Effectiveness of Garlic
(Allium sativum L.) and Hot Pepper (Capsicum frutescens L.) in the Management of the Major Pests of Cabbage Brassica oleraceae (L.). Sustainable Agriculture Research.5 (2): 83-91.

Baidoo, P., Mochiah, M., and Apusiga, K. 2012. Onion as a Pest Control Intercrop in Organic Cabbage (Brassica oleraceae) Production System in Ghana. Sustainable Agriculture Research. 1(1): 36-41.

Bernhoft, A. 2010. Bioactive compounds in plants - benefits and risks for man and animals. Oslo: The Norwegian Academy of Science and Letters.

Chaieb, I. 2010. Saponins as insecticides, A Review. Tunisia Journal of Plant Protectection.5(1):39-50.

De Geyter, E., Lambert, E., Geelen, D., and Smagghe, G. 2007. Novel advances with plant saponins as natural insecticides to control pest insects. Pest Technology.1(2): 96-105.

Devanand, P., and Rani, P. 2008. Biological potency of certain plant extracts in management of two lepidopteran pests of Ricinus communis L. Journal of Biopesticides.1(2): 170-176.

Devi, L., and Gupta, P. 2000. Evaluation of some plant latices against Heterodera cajani on cowpea Vigna sinensis. National Academy of Science.23(5/6): 65-67.

Dixon, R. A. 1999. ISO flavonoids: biochemistry, molecular biology, and biological functions. Elsevier. 773-823.

Dolui, A. K., Debnath, M., and De, B. 2010. Phytochemical and insecticidal screening of the leaf extracts of Heliotropium indicum L. Asian Journal of Chemistry.22(7): 5331-5334.

Ejikeme, C. M., Ezeonu, C. S., and Eboatu, A. N. 2014. Determination of physical and phytochemical constituents of some tropical timbers indigenous to Niger 
Delta Area of Nigeria. European Scientific Journal. 10(18): 247-270.

Facknath, S. 2006. Effects of phytoextracts and natural enemy to control Plutella xylostella L. (Lepidoptera: Plutellidae) in cabbage. Allelopathology Journal, 207221.

Feng, R., and Isman, B. 1995. Selection of resistance to azadirachtin in the green peach aphid, Myzus persicae. Experientia. 51(8): 831-833.

Goławska, S. 2006. Aphids and Other Hemipterous Insects. Poznan: Polish Entomological Society.

Halkier, B. A. 1999. Glucosinolates. New York: John Wiley and Sons.

Hedin, P., and Waage, S. K. 1986. Roles of flavonoids in plant resistance to insects In:Plant Flavonoids in Biology and Medicine:

Biochemical,

Pharmacological and Structure-Activity Relationships. Alan R. Liss, New York. Pp. 87-100).

Jacobs, M. A., Adeolu, R. J., and Yallapa, R. 2015. EntomoToxicity of Xylopia aethiopica and Aframomum melegueta in Suppressing Oviposition and Adult Emergence of Callasobruchus maculatus (Fabricus) (Coleopt Adult Emergence of Callasobruchus maculatus (Fabricus) (Coleoptera: Chrysomelidae) Infesting Stored. Jordan Journal of Biological Sciences. 8(4): 263 - 268.

Karamanoli, K., Bouligaraki, P., Constantinidou, H. I., and Lindow, S. E. 2011. Polyphenolic compounds on leaves limit iron availability availability and affect growth of epiphytic bacteria. Ann. Appl. Biol. 159(1): 99-108.

Kokate, C. K., Purohit, A. P., and Gokhale, S. B. 2010. Text Book of Pharmacognosy. Vol. 1 and 2, Nirali Prakashan, Pune, India.

Krings, U., and Berger, R. G. 2001. Antioxidant activity of roasted foods. Food Chem. 72(2): 223-229.
Miresmailli, S., and Isman, M. 2014. Botanical insecticides inspired by plantherbivore chemical interactions. Trends in Plant Science. 19(1): 29-35.

Mithofer, A., Boland, W. Plant defense against herbivores: Chemical aspects. Annu. Rev. Plant Biol. 2012; 63: 431450.

Naqqash, M., Gökçe, A. B., and Salim, M. 2016. Insecticide resistance and its molecular basis in urban insect pests. Parasitology Research. 115(4): 4898-9.

Ndam, L. M., Mih, A. M., Fongod, A. G., Tening, A. S., Tonjock, R. K., and Enang, J. E. 2014. Phytochemical screening of the bioactive compounds in twenty (20) Cameroonian medicinal plants. Int. J. Curr. Microbiol. App. Sci. 3 (12): 768-778.

Obadoni, B. O., and Ochuko, P. O. 2002. Phytochemical studies and comparative efficacy of the crude extracts of some haemostatic plants in Edo and Delta States of Nigeria. Global Journal of Pure and Applied Sciences. 8(2): 203-208.

Okwu, D. E. 2005. Phytochemicals, vitamins and mineral contents of two Nigeria medicinal plants. In: Int. J. Mol. Med. Adv. Sci. 1(4): 375-381.

Ramawat, K. G., and Dass, S. 2009. Ethnomedicine to Modern Medicine. Heidelberg: Springer-Verlag, Berlin.

Ramu, G., and Mohan, G. K. 2012. Preliminary phytochemical and antioxidant study of hydroalcoholic extracts from selected genera of Indian Lamiaceae. Asian Pacific J.Trop. Biomedicine. 77(6): 685-688.

Singh, R., Singh, S. K., and Arora, S. 2007. Evaluation of antioxidant potential of ethyl acetate extract/fractions of Acacia auriculiformis A. Cunn. Food Chem. Toxicol.45(7): 1216-1223.

Ssekyewa, C., Mwine, T., Kalanzi, F., and Kudamba, C. 2008. Efficacy of Indigenous botanicals in the management 
of cabbage pests in an organic farming systems. Proceedings of Science Conference.ISOFAR, Modena. Pp. 234236.

Tewary, D., Bhardwaj, A., and Shanker, A. 2005. Pesticidal activities in five medicinal plants collected from mid hills of western Himalayas. Journal of Horticulture. 22(3): 241-247.
Trease, G. E., and Evans, W. C. 2002. Allelopathic potentials of Echinacea angustifolia D. C. J. Experiment. Bot. 39-43.

Trease, G. E., and Evans, W. C. 2009. Pharmacognosy.Saunders/ Elsevier, sixteenth ed.Pp. 603-647.

\section{How to cite this article:}

Racheal Lamara, Morgan Andama and Eunice A. Olet. 2020. Phytochemical Composition of Aqueous Crude Extracts of Selected Pesticidal Plants used against Brassica Vegetable Pests. Int.J.Curr.Microbiol.App.Sci. 9(01): 468-478. doi: https://doi.org/10.20546/ijcmas.2020.901.051 